\title{
The Policy Challenge with Floating Exchange Rates: Turkey's Recent Experience
}

FARUK SELÇUK

faruk@bilkent.edu.tr

Department of Economics, Bilkent University, Bilkent, 06800, Ankara, Turkey

Key words: exchange rate volatility, float, intervention, developing economies

JEL Classification Numbers: C32, E31, E58, E65, F31

\begin{abstract}
This paper evaluates the developments in the Turkish economy in light of the Central Bank of Turkey's (CBT) policies during a recent period of floating exchange rate system (March 2001-July 2003). It is found that the CBT was effective in containing volatility and reducing the average inflation rate while there was a strong recovery of output. However, there are accumulated risks in the economy. Particularly, the extreme appreciation of the Turkish lira during this period and the record level of real interest rates give the impression that the current state of the economy is fragile. Unless the government accelerates the structural reform process and pursues sound fiscal policies to reduce the public sector borrowing requirement and the debt ratio, an adverse shock to the system may trigger a reversal of fortune.
\end{abstract}

Imagine an economy with an ever-rising domestic debt and record real interest rates, a high and persistent inflation, an extremely weak and shallow banking sector (occasionally, with some corrupt bankers), political instability, and a geographical location with constant turmoil in neighboring countries. On top of this, add a dramatic collapse of a fixed exchange rate based stabilization program which resulted in a market-forced devaluation followed by a floating exchange rate regime. Is it possible to conduct a policy such that the volatility of the exchange rate may be contained and the implicit inflation targeting may result in significantly lower inflation rates while real output growth picks up? The recent developments in the Turkish economy show that the answer is yes but with a significant risk remaining in the economy.

February 19, 2001 was a major turning point in Turkish political and economic history. That day, Turkish Prime Minister Bulent Ecevit announced that there was a serious "dispute" between himself and the country's President. He further emphasized that "of course, this is a serious political crisis" without elaborating the future of the government or the ongoing stabilization program which aimed at lowering inflation with a fixed nominal exchange rate depreciation. The same day the stock market dived 18 percent and the Central Bank of 
Turkey (CBT) sold USD 7.5 billion, approximately one-third of the total official reserves, for next-day delivery to banks. Two state banks (Ziraat and Halkbank) were not able to meet their TRL obligations the following day and the CBT refused to provide Turkish Lira liquidity to these or other banks. As a result, banks were forced to sell USD 6 billion back to the CBT. The daily average overnight interest rates rocketed up to (simple annual) 2000 percent on February 20, and 4000 percent on February $21 .{ }^{1}$ The government could not resist and dropped its exchange-rate controls early February 22 and the TRL/USD exchange rate went up 40 percent in one week. Monthly inflation in March was 10 percent, followed by a monthly inflation of 14 percent in April 2001. The government prepared a new letter of intent to the IMF, emphasizing a major overhaul in the banking system and a promise of further acceleration of structural reforms outlined in earlier letters of intent. On May 15, 2001, the IMF approved this revision of Turkey's three-year Stand-By arrangement by USD 8 billion with an understanding that the country moved into a floating exchange rate regime, and would stick to this policy.

The challenge for the CBT was to re-establish confidence and to contain volatility in financial markets while pursuing an implicit inflation targeting policy in a free floating exchange rate system. It was a challenge in the sense that the country had a long history of high inflation, and had never experienced a free float. Nominal exchange rates almost always increased in line with high inflation. The recent collapse of the fixed exchange rate stabilization program probably weakened the credibility of the CBT and led economic agents to re-enforce their belief that any policy announcement by the authorities is not credible and the policy may one day be reversed. ${ }^{2}$

This paper evaluates developments in the foreign exchange market and inflation in light of the CBT's policies during the recent floating exchange rate system in Turkey. It is found that the CBT was effective in containing volatility and reducing the average inflation rate. However, there are accumulated risks in the economy. Particularly, the extreme appreciation of the TRL during this period and the record level of real interest rates give the impression that the current state of the economy is one of unstable equilibrium. Unless the government pursues sound fiscal policies to reduce the public sector borrowing requirement and the debt ratio, any adverse shock to the system may trigger a new financial and real crisis. Also, both the public sector and the legal environment need a major shake-up to bring the current infrastructure closer to those of developed economies. In this new framework, the economy may attract significant long-term productive capital, and the overall productivity increase in recent months may accelerate, dampening the potential negative effect of real appreciation. In short, the monetary authority during the float seems to have done its best and the burden remains with the government in general and the fiscal authority in particular.

The paper is organized as follows. The next section investigates the interaction among foreign exchange rate, its volatility, and the CBT's policies using 
daily data in a vector autoregression (VAR) framework. Section 2 looks at the relation between the exchange rate and inflation. Section 3 reports on the real exchange rate and growth dynamics employing a bivariate VAR model. The last section summarizes the findings and concludes.

\section{Containing volatility}

In several press releases and announcements regarding the monetary and exchange rate policies after February 2001, the CBT insisted that the monetary authority would stick with the floating exchange rate regime, and pursue an implicit inflation targeting policy by controlling the monetary aggregates and setting an indicative interest rate. On several occasions, the CBT made it clear that under no circumstances the level or the direction of nominal exchange rates will be a target but the volatility of the nominal exchange rates would be a concern (CBT, 2002, 2003). Although the CBT did not spell out any specific nominal exchange rate, our initial analysis showed that it was mostly the TRL/USD volatility. According to announcements, any increase in volatility would be contained through foreign exchange buying and selling auctions and other forms of transparent interventions. To this end, the CBT conducted several buying and selling auctions in three distinct periods (see Figure 1). All selling auctions took place between March 29, 2001 and November 30, 2001, during the early stages of float. Total amount sold in these auctions was USD 6,553 million. Later, there were only buying auctions. The first series of these buying auctions took place between April 4 and June 6, 2002. The second period started on May 5, 2003 and continued as of August 2003. The CBT bought back USD 2,755 million until June 31, 2003, and is planning to buy another USD 1 billion in August 2003. The Bank also directly intervened in the market four times between May 12 and July 18, 2003 by buying USD 2,083 million. ${ }^{3}$ Overall, the CBT seems to have bought back (USD 5,838 million) a significant portion of the reserves sold during the float (USD 6,553 million) with small differences between buying and selling prices: the weighted average of auction selling prices was (TRL/USD) $1.3 \mathrm{~m}$ in 2001. The weighted averages of auction buying prices were $1.42 \mathrm{~m}$ in 2002, and again $1.42 \mathrm{~m}$ in 2003.

A close inspection of the daily exchange rate, its return and volatility (defined as the daily absolute return) shows that the monetary authority indeed was successful at reducing the volatility (see Figure 1, panel (c)). ${ }^{4}$ Meanwhile, the CBT was able to lower its overnight interest rates from 122 percent in March 2001 to 38 percent in August 2003 in line with falling inflation and increasing confidence in the economy.

\subsection{A VAR model}

In order to investigate the interaction among the foreign exchange rate, its volatility, and the CBT policies, a five variable VAR system is estimated using 

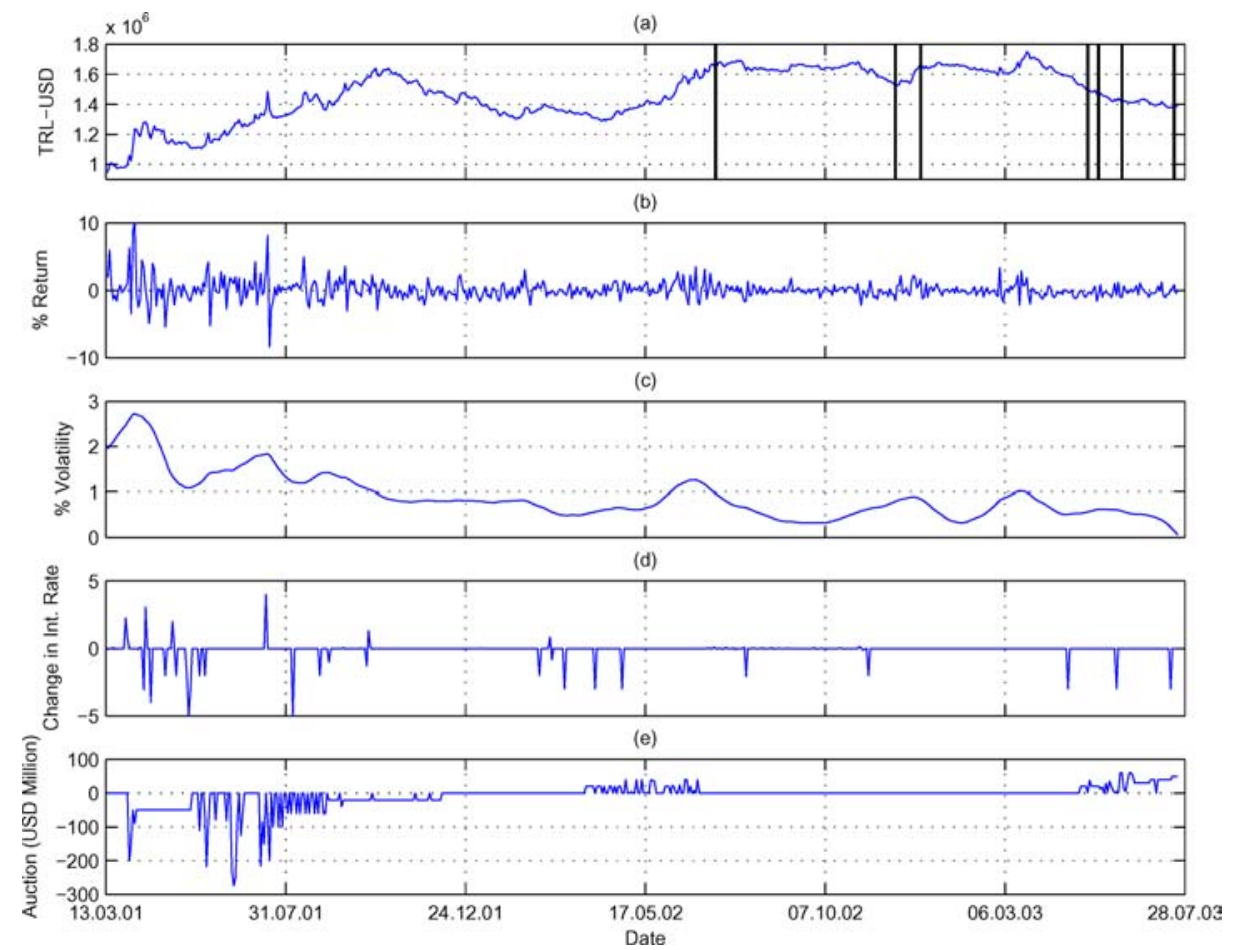

Figure 1. Floating exchange rate period and the CBT. Daily. (a) TRL/USD exchange rate. (b) TRL/USD exchange rate return (percent). (c) TRL/USD volatility (zero-phase filtered absolute return, percent) (d) Change in overnight interest rate (percent). (e) CBT exchange rate buying (positive) and selling (negative) auctions (USD million). There were seven direct interventions of the CBT: July 11, 2002 (selling); December 2, 2002 (buying); December 24, 2002 (selling); May 12, 2003 (buying); May 21, 2003 (buying); June 9, 2003 (buying); July 18, 2003 (buying). These dates are shown as vertical lines in the top panel. Sample period: March 12, 2001-July 22, 2003 (597 business days). Data source: The CBT of Turkey.

daily data. The VAR system may be viewed as a reduced form of a structural system of equations. In this particular case, the CBT is assumed to have a policy function to contain the nominal exchange rate volatility in the market. In setting its policy tools (buying and selling auctions and interest rate), the CBT is assumed to observe the change in exchange rate and volatility. The variables in the system are the TRL/USD exchange rate return (log difference, percent), the absolute value of the exchange rate return as a measure of volatility (percent), the change in the CBT overnight interest rates (simple annual, percent), the daily total amount bought by the CBT in USD buying auctions and the amount sold by the CBT in USD selling auctions (million USD). ${ }^{5}$ The system is estimated with a constant term and 11 lags, as indicated by the Sims' Likelihood Ratio (LR) test (Sims, 1980), for the sample period of March 13, 2001-July 22, 2003 (596 business days). 
The TRL/USD exchange rate return is placed first in the order of variables. That is, we assume that exchange rate innovations at daily frequency are generated by exogenous market shocks. Because of this assumption, the Cholesky decomposition of the variance covariance matrix of innovations implies that orthogonalized innovations to the exchange rate depend solely on the residuals from the exchange rate equation. For other variables, the disturbance term is a mixture of shocks, including the exchange rate return shock. The CBT policy tools are naturally placed after the exchange rate and volatility. The Granger causality tests indicate that the exchange rate return causes the change in the interest rate at 5 percent significance level. Similarly, the selling auction causes volatility at 1 percent. Adjusted R-squares lie within the range of 0.08 (change in interest rate equation) and 0.68 (buying auctions equation). These results indicate that the CBT followed developments in the exchange rate market and inflation when making its interest rate cutting decisions. However, it was proactive on volatility through its selling auctions.

Figure 2 plots the estimated response of the exchange rate return to different shocks in the system along with 95 percent bootstrap confidence levels. The response of the exchange rate return to shocks to the interest rate change or to the volatility are not statistically significant. On the other hand, the response of exchange rate return to a shock to the buying auction is negative and statistically significant for one period. There is no further response to a shock to the selling auction. Similarly, when direct USD buying interventions of the CBT are included in the system, the estimated coefficients and responses of other variables to a shock to the direct intervention were not statistically significant. Normally, one would expect that the response of the exchange rate return to the CBT's buying actions would be positive. The negative response here indicates that the CBT is not influencing the direction of the exchange rate with its buying decision but simply accumulating reserves by taking advantage of the falling exchange rates. On the other hand, the response of the exchange rate return to a shock to the selling auction is negative for the first three periods. The response reverses itself and becomes positive for two periods and the overall response is close to zero. We may conclude that the CBT interventions, either buying or selling, did not affect the direction of the exchange rates. ${ }^{6}$

Figure 3 reports the volatility impulse responses to different shocks. The response of volatility to a shock to the foreign exchange return is positive and statistically significant for several periods, i.e., an unexpected increase in the exchange rate causes an increase in volatility. The symmetric nature of impulse responses implies that a a fall in the exchange rate return decreases the volatility. Also, the volatility of the exchange rate responds positively to a positive shock to the interest rate change (an increase). Giving the symmetric nature of impulse responses, this implies that the CBT's interest rate policy (cutting interest rates in a sporadic fashion) reduced the volatility in the market. Similarly, the response of volatility to a shock to buying auctions is negative and statistically significant, indicating that the CBT tamed the 

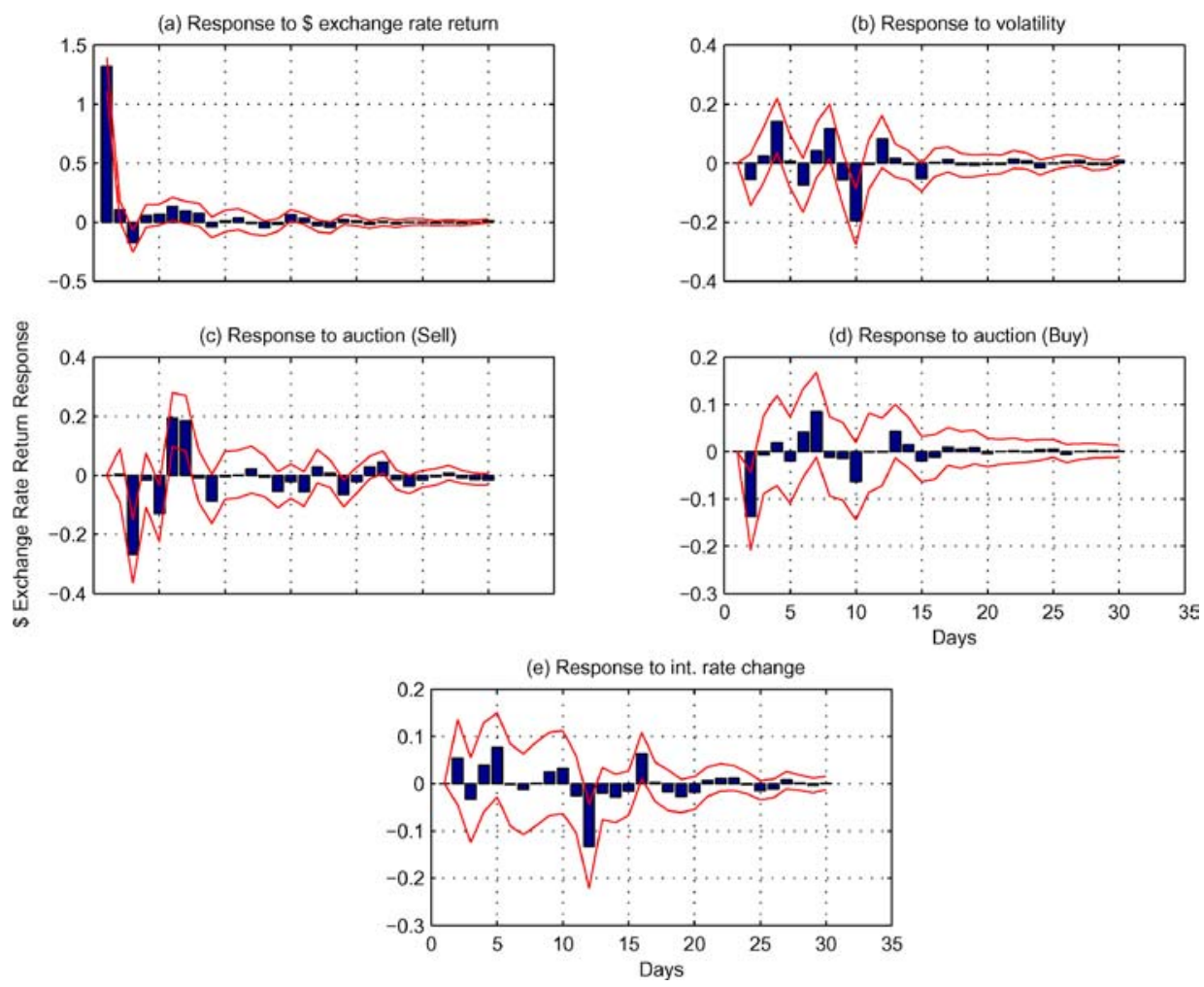

Figure 2. TRL/USD daily exchange rate return (log difference) response to shocks to different variables in the system. (a) Response to a shock (1.37 percent increase) in TRL/USD daily exchange rate return. (b) Response to a shock ( 0.90 percent increase) in TRL/USD daily volatility (absolute return). (c) Response to a shock (23 million USD increase) in CBT USD selling auction. (d) Response to a shock (7 million USD increase) in CBT buying auction. (e) Response to a shock (0.57 percent increase) in change in overnight interest rates. 95 percent bootstrap confidence intervals are plotted as straight lines. Sample period: March 13, 2001-July 22, 2003 (596 business days).

volatility through its selling auctions. On the other hand, the impulse response of volatility to a shock to the buying auction is not statistically significant, i.e., the CBT accumulated its foreign exchange reserves through buying auctions without influencing the volatility. These findings provide support to the CBT's claim that the monetary authority was concerned only about the exchange rate volatility, not the level or direction of exchange rates, and conducted its policy accordingly.

The results in this part are in line with previous findings. Domaç and Mendoza (2002) estimated an Exponential GARCH model using daily data on foreign exchange intervention in Turkey and Mexico. Using a smaller sample (February 2001-May 2002), they showed that both the amount and frequency of foreign 

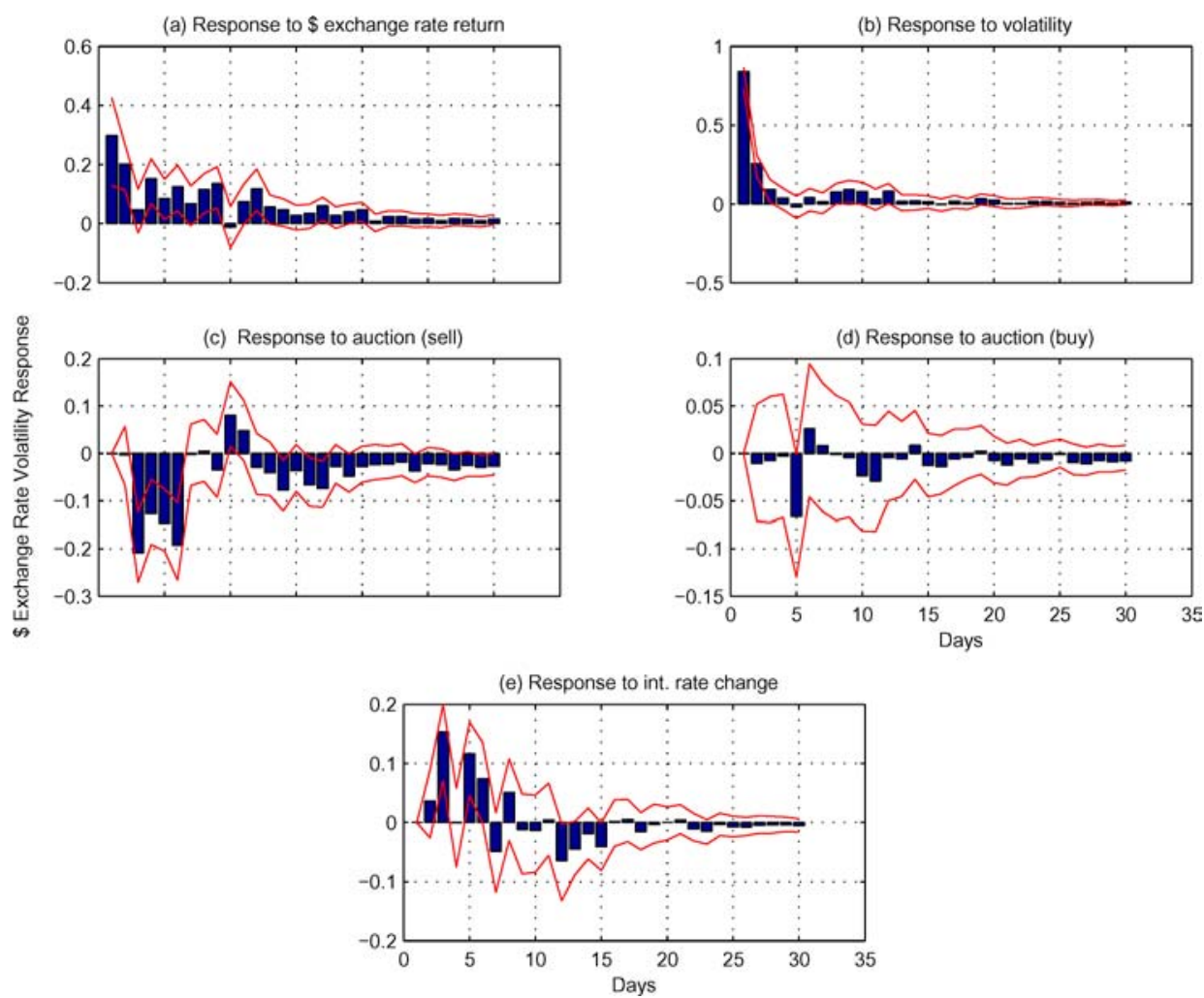

Figure 3. TRL/USD daily exchange rate volatility (absolute value of log difference) responses to shocks to different variables in the system. (a) Response to a shock ( 1.37 percent increase) in TRL/USD daily exchange rate return. (b) Response to a shock ( 0.90 percent increase) in TRL/USD daily volatility (absolute return). (c) Response to a shock ( 23 million USD increase) in CBT USD selling auction. (d) Response to a shock (7 million USD increase) in CBT buying auction. (e) Response to a shock ( 0.57 percent increase) in change in overnight interest rates. 95 percent bootstrap confidence intervals are plotted as straight lines. Sample period: March 13, 2001-July 22, 2003 (596 business days).

exchange intervention decreased the volatility of the exchange rates in Turkey. Domaç and Mendoza (2002) reported that their results also imply that sale operations are effective in influencing the exchange rate and its volatility, while purchase operations are found to be statistically insignificant in affecting the exchange rate and its volatility.

\subsection{Reverse currency substitution?}

The degree of currency substitution (or dollarization) plays an important role in determining a stabilization policy and conducting monetary policy in a 
high-inflation economy with currency substitution. Particularly, the demand for domestic money becomes unstable and makes it hard to conduct a disinflationary monetary policy to fight inflation. ${ }^{7}$ Several studies on currency substitution in Turkey show that the elasticity of substitution between domestic and foreign currencies is high and significant; see, for example, Domaç and BahmaniOskooee (2002), Selçuk (2003) and references therein. A positive shock to currency substitution initially decreases the monetary base but later increases it to generate an inflation tax at a given level of budget deficit. The decline in the inflation tax resulting from increasing currency substitution is in part compensated by administrated prices which in turn causes an increase in inflation (Domaç and Bahmani-Oskooee, 2002). Eventually, the economy enters into a vicious circle and remains almost always on the wrong side of the inflation tax Laffer curve (Selçuk, 2001). However, the process is not irreversible in Turkey: there is still room to implement a sound stabilization policy and obtain a significant seigniorage income as a result of reverse currency substitution (Us, 2003).

There are several determinants of currency substitution. The interest rate differential stands out as one of the most important one. Consider the overnight return, $r d_{t}$, on a USD short position in Turkey during the float:

$$
1+r d_{t}=\frac{1+r_{t}}{1+e_{t}}
$$

where $r d_{t}$ is the daily return on a USD short position, $r_{t}$ is the overnight TRL borrowing rate of the CBT and $e_{t}$ is daily percent change in the TRL/USD exchange rate. The geometric average of Equation 1 after the float is 1.0008737 which implies a 37 percent (compounded) annual rate of return in USD terms. Given this record level of interest rate on a long TRL position vs. USD, it is reasonable to expect some form of reverse currency substitution. However, traditional measures of currency substitution indicate that there was not much of a reverse currency substitution during the float. The most common measure of currency substitution in the literature is the ratio of "foreign currency denominated deposits" to "M2 money stock plus foreign currency denominated deposits". Notice that this measure does not include the foreign currency in circulation since it is difficult to find a consistent time series on this variable. The currency substitution ratio hovered within the range of 40-50 percent between 1993 and 2001 with an average of 47 percent. After the crisis of February 2001, the ratio increased sharply and came close to its historical record level of 64 percent in October 2001, thanks to a sharp increase in the nominal exchange rate and corresponding increase in the TRL value of foreign exchange deposits. Since then, the ratio has been decreasing (with the exception of May-August 2002 period) at a steady fashion. Nevertheless, it is still 47 percent, suggesting that the ratio is reverting to its long-run mean. On the other hand, the level of foreign currency denominated deposits are at their highest level ever: USD 44.8 billion in July 2003. The same figure was USD 36 billion at the end of 2000, before the February 2001 crisis. 
Therefore, "reverse currency substitution", if any, must come from somewhere else.

Corruption, to the extent that it undermines confidence in the economy, may have an impact on currency substitution as well. There are already encouraging signs that the government is serious in taking radical measures to fight corruption and to restructure the public sector. A voluminous report by a parliamentary committee lists hundreds of cases of wrong-doing and corruption in the public sector and recommends further investigation and restructuring. Recently, a criminal case was opened against a local tycoon, Uzan family, when a series of investigations revealed that the group siphoned approximately USD 3.5 billion from the family owned bank. The family engaged in dubious activities across various lines of businesses for a long period of time but the previous authorities remained silent. These developments and on-going fiscal discipline are welcomed by both domestic and foreign investors, and have increased the confidence in authorities.

A recent study by the Federal Reserve reports that around 60 percent of all U.S. currency, or about USD 365 billion, is held outside the United States (FED, 2003). In that study, Turkey ranks as the fifth largest U.S. currency holder with an estimated USD 10 billion in circulation. ${ }^{8}$ Coincidentally, M1 money stock in Turkey (end of 2002) is also around USD 10 billion. As our causal observations suggest that the U.S. currency in circulation in Turkey as a medium of exchange is only a small fraction of the Turkish lira in circulation, we may assume that a significant portion of the U.S. currency is held as a "store of value" which is labeled as "under the mattress" dollars.

During the float, economic agents realized for the first time in 20 years that there was a downward risk of holding a foreign currency. The average monthly change in TRL/USD exchange rate 4 percent between January 1980 December 2000 (252 months). All monthly changes during this period were positive, except some small corrections for 1-2 months following a large increase in exchange rates. After the float (May 2001-July 2003), the same monthly average was 0.6 percent with 14 months of negative and 13 months of positive change. In addition to this uncertainty, a severe recession in 2001 and a sharp drop in real income and real wealth as a result of the jump in general price level might have caused households to liquidate part of their wealth, accumulated as precautionary savings in the form of U.S. currency. The CBT, which has direct access to information about the flow of funds seems to acknowledge this idea: "During this period [i.e., the first quarter of 2002], an apparent reverse currency substitution started in line with the improvement in inflation and inflation expectations. In other words, residents began converting their foreign currency savings into Turkish-lira denominated investment instruments" (CBT, 2003, p. 14). It is worth nothing that the amount of foreign currency deposits did not change at all and stood at USD 41 billion during the referred period. More recently, the bank justified its foreign exchange buying auctions and direct buying interventions in 2003 stating once again that there was a "reverse currency substitution". Again, 
the foreign exchange deposits at the end of July 2003 (USD 44.8 billion) were slightly higher than in December 2002 (USD 44.3 billion) suggesting that the CB statements must be referring to some other sources of dollars, such as "dollars under the mattress" or "dollars across the borders": there were rumors and speculative reports in the press that the war in Iraq (March 2003) caused a significant cross-border, hard-currency transfer to Turkey from Iraq. Although these reports have never been confirmed, it is evident that there was some hard-cash floating around the region:

"David Aufhauser, the U.S. Treasury's general counsel, says records kept by [Iraqi] central bank officials indicated that it is probable that USD 850 million in banknotes found by U.S. troops in Baghdad in April was part of the hoard removed from the bank by Saddam Huseyin's son Qusay" (Reuters, 2003). ${ }^{9}$

Net Errors and Omissions item in the balance of payments shows that there was a USD 3.5 billion (approximately 12 percent of the GBT reserves) inflow into the system from some unknown sources between March and June 2003. Although some part of this inflow is probably what left the system in January and February 2003 (USD 2.3 billion) out of war fears, the net inflow of foreign currency during the first half of 2003 (USD 1.2 billion) is still significant, and remains to be explained.

In any case, we may conclude that particularly the supply of foreign exchange in the market helped the monetary authority both in containing volatility through effective interventions and reducing inflation through lower nominal appreciation. The next section investigates the interaction between exchange rate and inflation. ${ }^{10}$

\section{Exchange rates and inflation}

In a recent letter of intent to the IMF, the CBT announced that it was preparing to move toward an explicit inflation targeting policy in the near future. Since one of the stated goals of the CBT is to contain the volatility but not the level or the direction of the exchange rates, it is important to investigate the relation between exchange rates and inflation because the degree of exchange rate pass-through in the economy should be a concern for the inflation targeting authorities. Strictly speaking, the term "exchange rate pass-through" means "transmission of a change in import prices to the prices of imported goods". In this section, we use the term to denote the effect of a change in nominal exchange rates on domestic inflation. Since not all the goods and services in the economy are tradeable, the estimated exchange rate pass-through coefficients reported below are biased and should be interpreted with caution.

Figure 4 plots the monthly percentage change of a nominal exchange rate basket $^{11}$ and inflation in Turkey between February 1994 and June 2003. All three series are filtered with a 12-period, zero-phase filter to determine the basic 


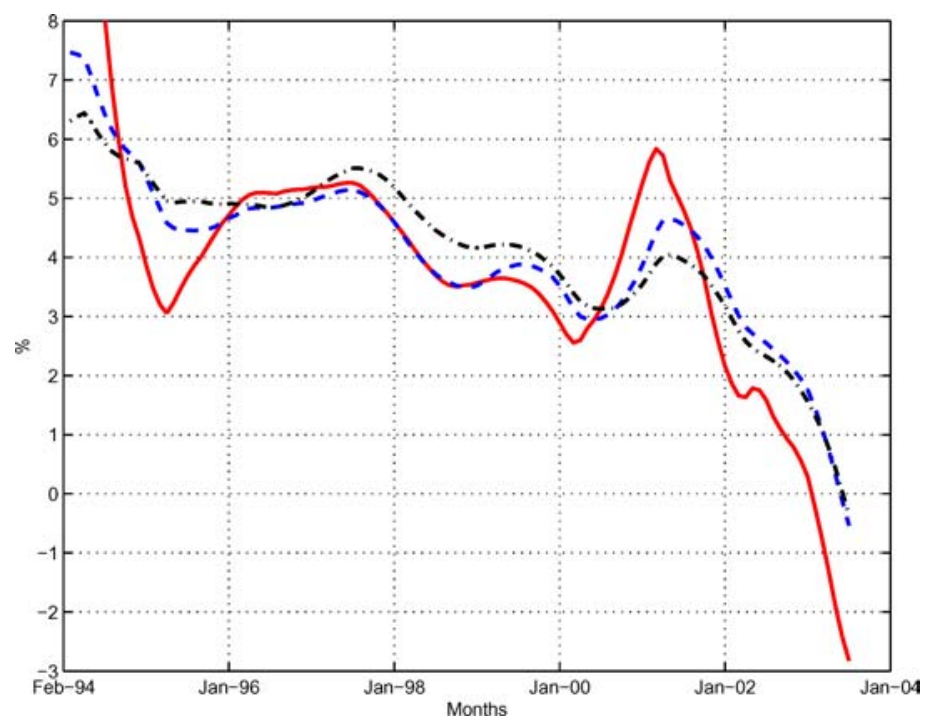

Figure 4. Monthly change in exchange rate (solid) and monthly inflation (dashed: WPI inflation, dash dot: CPI inflation). The exchange rate is a basket of TRL/USD and TRL/EUR (TRL/DEM before 2001) with weights as explained in the text. All series are filtered with a zero-phase filter (see, Note 4). Sample period: February 1994-July 2003 (114 months). Data source: The CBT.

turning points (see Note 4). The first thing we notice is that the exchange rate and the price level move in tandem even in the short run. However, a fall in the monthly exchange rate return is not followed by a one-to-one fall in the inflation rate; the monthly inflation rate (especially $\mathrm{CPI}$ inflation) remains higher (see, for example, 1994-1996; 1998-2000 periods and most recent dates). In other words, a slowdown in the exchange rate is usually followed by a slowdown in the price level but inflation remains higher than the percentage change in the exchange rate for a considerable period of time. This means that the Turkish lira appreciates significantly in real terms during relatively slowed-down nominal depreciation periods. This is consistent with a small degree of exchange rate pass-through and confirms the findings of other studies (see, for example, Leigh and Rossi, 2002).

In order to analyze the nominal exchange rate and inflation interaction, a three variable VAR model is estimated with monthly data for the sample period February 1994-July 2003 (114 months). As noted by Faruqee (2004), the VAR methodology potentially allows one to identify specific "structural" shocks affecting the system. In this case, a structural exchange rate shock is identified through a Cholesky decomposition of innovations, where exchange rate fluctuations are assumed to be largely driven by exogenous asset market disturbances. Faruqee (2004) also showed that impulse-response functions from the VAR estimates can also be used to identify-in a "new open economy macroeconomics model"-those key behavioral parameters that best replicate the 

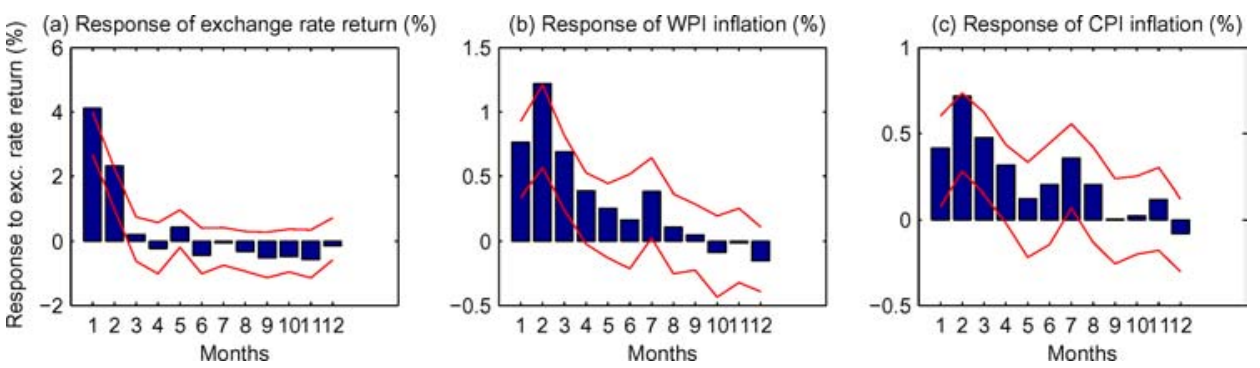

Figure 5. Responses to a shock (4 percent increase) in monthly exchange rate. (a) Response of exchange rate. (b) Response of WPI monthly inflation. (c) Response of CPI monthly inflation. Exchange rate is a basket of TRL/USD and TRL/EUR (TRL/DEM before 2001) with weight as explained in the text. All responses are in percentage terms: An unexpected 4 percent increase in exchange rate basket results in 2.3 percent increase in exchange rate following month. The same shock results in an overall 3 percent increase in monthly WPI inflation and 1.9 percent increase in CPI inflation during the following 4 months. 95 percent bootstrap confidence intervals are plotted as straight lines. Sample period: February 1994-July 2003 (114 months).

pattern of exchange rate pass-through. In other words, impulse-response functions from the VAR estimates may provide a guideline to construct and to calibrate a detailed structural model.

The variables are the monthly percentage changes of the nominal exchange rate basket (FX) as explained above and monthly inflations, calculated from the wholesale price index (WPI) and the consumer price index (CPI). The system is estimated with 12 lags, as indicated by the LR test. The results show that there is a feedback between WPI inflation and CPI inflation but there is no Grangercausality among variables. Adjusted R-squares are 0.18 (FX equation), 0.41 (WPI inflation equation) and 0.37 (CPI inflation equation).

Figure 5 plots the responses of the variables to a shock to the monthly percent change in the nominal exchange rate basket, along with 95 percent bootstrap confidence intervals. An unexpected 4 percent increase in the exchange rate basket results in 2.3 percent increase in the exchange rate the following month. After the second month, the responses are not statistically significant. The same shock results in an overall 3 percent increase in the monthly WPI inflation and 1.9 percent increase in the CPI inflation during the following 4 months. After the fourth month, the responses are not statistically significant. These findings imply that the exchange rate pass-through is around 50 percent for the WPI inflation and 35 percent for the $\mathrm{CPI}$ inflation. A recent study on the same subject reports very similar pass-through coefficients in Turkey: 50 percent for the WPI inflation and 40 percent for the CPI inflation (Leigh and Rossi, 2002).

Devereux and Lane (2003) showed that if the exchange rate pass-through is low, both output volatility and inflation volatility in a floating exchange rate regime may be lower than under a fixed exchange rate regime. They conclude that a low rate of exchange rate pass-through may be an important prerequisite for the success of inflation targeting in emerging markets. The relatively 
low exchange rate pass-through coefficients in Turkey show that the Turkish economy meets this prerequisite.

It is clear from Figure 4 that there is a substantial decrease in monthly inflation during the float. The question is: how much of the decrease in inflation may be attributed to the fall in nominal exchange rate. The average monthly change in the nominal exchange rate basket went down from 6 percent in March 2001 to -2.8 percent in July 2003. During the same period, the average monthly inflation went down from 4 percent (CPI) (4.5 percent WPI inflation) to -0.5 percent. That is, the change in the average monthly CPI inflation was 51 percent of the average monthly percentage change in the nominal exchange rate during the same period. This figure is significantly higher than the estimated exchange rate pass through for the CPI inflation which means that the fall in the average CPI inflation during the float cannot be attributed solely to exchange rate dynamics. Similarly, the change in the average WPI inflation is 57 percent of the average percent change in the nominal exchange rate basket which is slightly higher than the estimated exchange rate pass-through.

The positive difference between the average inflation and the percent change in the nominal exchange rate basket implies that the Turkish lira appreciated significantly during the float. The next section looks at the real exchange rate and growth dynamics.

\section{Real exchange rate and growth}

There was a substantial increase in the nominal exchange rate during the early days of the floating exchange rate regime which caused a significant real depreciation of the Turkish lira (approximately 25 percent from February to April 2001). This development led some people, especially from export and tourism sectors, to argue that the CBT should keep the exchange rate at "competitive" levels. In other words, there was "fear of floating" and "fear of real appreciation": all previous crashes in Turkey came after a substantial real appreciation of the domestic currency. It was argued that the CBT should target the real exchange rate (both the nominal exchange rate and price level) in its policies. ${ }^{12}$ The CBT, however, did not change its policy, mindful of the principle that with free capital mobility, it is impossible to control the exchange rate and run an independent monetary policy at the same time.

The initial real depreciation was reversed and the real exchange rate came back to its pre-crisis level on January 2002, exactly one year after the crisis. Although there were some fluctuations, real appreciation continued and the real exchange rate, as of August 2003, was 25 percent higher than its 1989-2000 average. ${ }^{13}$

The Turkish economy is a textbook case of boom-bust cycles generated in part by real exchange dynamics, especially after the capital-account liberalization. ${ }^{14}$ As reported by Ertuğrul and Selçuk (2002), after a positive shock to the real exchange rate (an appreciation), the interest rate parity condition leads to a 
lower domestic real interest rate. In turn, this results in an increase in domestic demand, especially in private durable and semi-durable goods consumption and private investment. As a result, the economy starts to expand. On the other hand, the demand for imported goods increases and the current account registers a deficit. Eventually, a reduction in consumption and investment, and a real depreciation is inevitable because of resource constraints. Therefore, the economy experiences a recession with the "correction" in the nominal (and real) exchange rate.

To analyze the interaction between the real growth rate and the real exchange rate in Turkey, we follow Kamin and Rogers (2000) closely and estimate a bivariate VAR model with quarterly data for the sample period of 1987.1-2003.1. ${ }^{15}$ Our aim is not to identify the channels by which the real exchange rate affects output (or vice versa) but rather to summarize the bivariate dynamics of the two macroeconomic variables. A VAR system serves our purpose as it does not impose any structure on the system. The variables are the quarterly percentage change in the real exchange rate index (JP Morgan Real Effective Exchange Rate Index, $1990=100$ ) and year-to-year real GDP growth in each quarter. The lag length is 3 as indicated by the Sims' LR test. The Granger-causality test results show that there is a feedback between two variables.

Figure 6 plots the impulse responses from this model. The first thing we notice is the cyclical nature of the response of real growth rate to a shock to the real exchange rate. The response of real growth rate to a 5 percent real appreciation shock is positive and significant for four quarters. Overall, this appreciation results in a 2 percentage point increase in yearly growth rate for one year. After five quarters, the response reverses itself and the effect is a 1 percentage point decrease in the yearly growth rate for the following three quarters. After two years, the response is not statistically significant. The net effect of a 5 percent real appreciation is a 1 percentage point increase in the growth rate in two years.

The response of the real growth rate to a real depreciation is negative, i.e., a contraction in the economy. This finding is in line with Berument and Pasaogullari (2003) who also reported that the effect of real depreciation on the economic performance of Turkey between 1987:I to 2001:III is contractionary. A real devaluation raises the real domestic currency value of a country's foreign-currency liabilities, inducing balance-sheet adjustments that may lead to a reduced domestic demand (Kamin and Rogers, 2000; Cavallo et al., 2002; Allen et al., 2002). Another possible reason for contraction in the economy may be real-balance effects: if the money supply lags the increase in the price level following an increase in exchange rates, its real value, and consequently the aggregate demand falls.

Kamin and Rogers (2000) reported similar results for Mexico: the real devaluation led to high inflation and economic contraction in Mexico, which implies substantial risks in targeting the exchange rate at too competitive a level. Since real exchange rate depreciations are inflationary in Turkey (Berument 

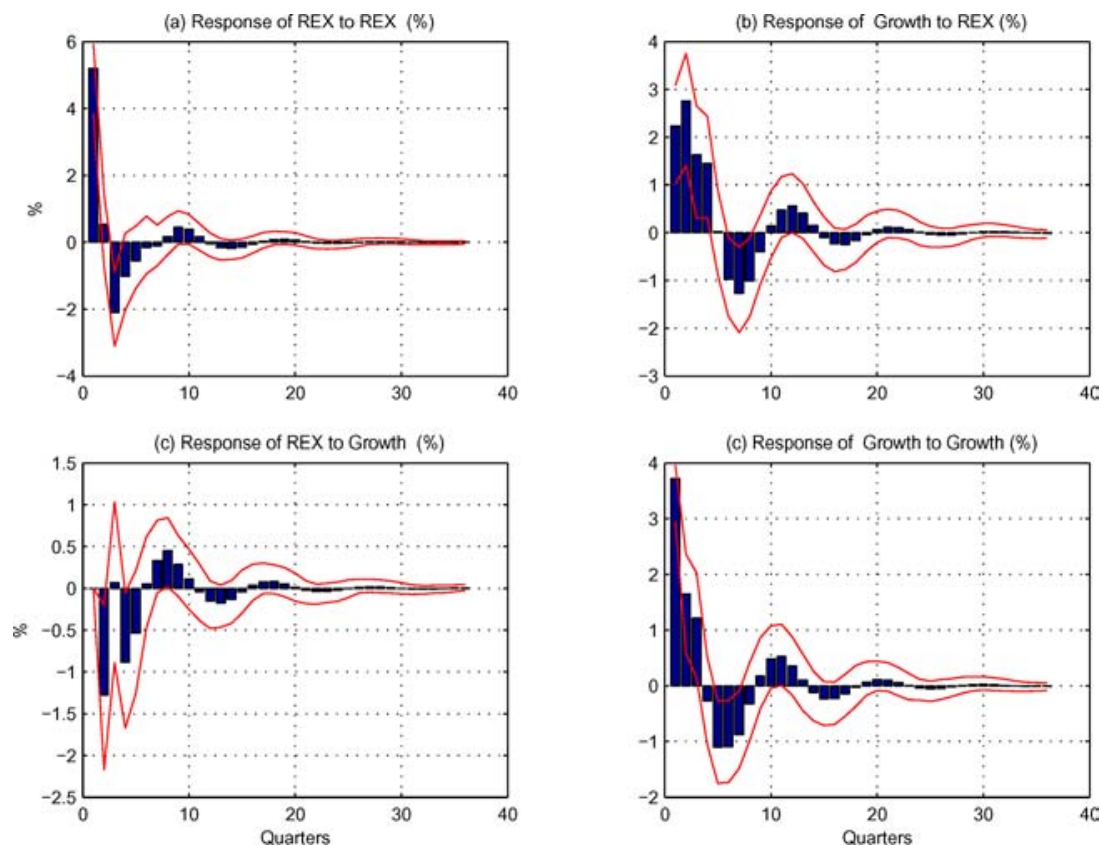

Figure 6. Real exchange rate (log difference) and real growth interaction. (a) Response of real exchange rate to a 5 percent positive stock (appreciation) to real exchange rate (percent). (b) Response of real growth rate to a 5 percent shock to real exchange rate (percent). (c) Response of real exchange rate to a 3.8 percentage point positive shock to growth rate (percent). (d) Response of growth rate to a shock to growth rate (percent). 95 percent bootstrap confidence intervals are plotted as straight lines. Sample period: February 1994-July 2003 (114 months).

and Pasaogullari, 2003), we may conclude that a real exchange rate targeting is riskier than inflation targeting in terms of output costs and higher inflation.

\section{Conclusion}

This paper has evaluated the developments in the foreign exchange market and inflation in light of the CBT policies during the recent floating exchange rate system in Turkey.

The estimation results indicate that the CBT was effective in containing volatility and reducing the average inflation rate. The bank followed the developments in the exchange rate market (and possibly inflation) when making its interest rate cutting decisions. However, it was proactive on volatility through its selling auctions. On the other hand, the CBT interventions, either buying or selling, do not seem to have had an effect on the direction of the exchange rates. These findings provide support to the CBT's claim that they were only concerned about the exchange rate volatility, not the level or direction of exchange rates. Although 
conventional measures do not indicate a strong reverse currency substitution, particularly the supply of foreign exchange in the market may have helped the monetary authority both in containing volatility through effective interventions and reducing inflation through lower nominal appreciation.

It was also shown that the degree of exchange rate pass-through is low in Turkey and that has helped the monetary authority to switch into an explicit inflation targeting policy. During the implicit inflation targeting period after February 2001, the average CPI and WPI inflation rates went down. The fall in the WPI inflation was mostly due to the lower nominal exchange rate depreciation. However, the fall in the average CPI inflation cannot be attributed solely to exchange rate dynamics.

The negative effect of the substantial appreciation of the Turkish lira on external competitiveness during the float was offset to a large extent by an increase in productivity and a fall in real wages. This signals that the government should take further action to reduce the debt-ratio and real interest rates, and to accelerate structural reforms to attract foreign direct investment. Otherwise, the float period may be just another episode of appreciation-depreciation and boom-bust cycles in the Turkish economy.

\section{Acknowledgments}

The author thanks an anonymous referee and Michele Fratianni (the editor) for helpful comments and suggestions. Financial support from the Research Development Grant Program of Bilkent University is gratefully acknowledged.

Editors' Note: We regret to report that Professor Selcuk passed away suddenly after the acceptance of his article.

\section{Notes}

1. These are weighted average interest rates. The highest realized overnight interest rates during these two days were 2300 and 6200 percent (simple annual). In other words, one-night TRL borrowing cost some banks 6.4 percent and 17.2 percent, respectively.

2. Gençay and Selçuk (2005) provide an anecdotal story of the February 2001 crisis in Turkey. For a detailed account of recent developments in the Turkish economy from different perspectives, see Alper and Öniş (2003), Ertuğrul and Selçuk (2002), Metin-Özcan et al. (2001), and references therein. A series of articles in Kibritçioğlu et al. (2002) provides a detailed analysis of inflation dynamics and disinflation efforts in Turkey. For earlier studies, see Metin (1995) and Lim and Papi (1997). More recent studies are Celasun et al. (2003) and Domaç and Bahmani-Oskooee (2002).

3. There were three direct interventions in 2002 (one buying and two selling). However, the amounts involved in these interventions are not known.

4. In order to determine basic turning points in the volatility series in Figure 1, the original data is filtered with a 20 -day equally weighted zero-phase filter. See Gençay et al. $(2001$, p. 95) for more details of this filter. 
5. Our preliminary investigation showed that the variables in the system are stationary. The full estimation results in this and following sections are not reported in order to save space. They are available from the author upon request.

6. There is a large literature that does not believe that sterilized interventions have any effect on foreign exchange returns in developed markets. However, it is reasonable to expect that the CBT would influence the direction of the nominal exchange rates in Turkey since the foreign exchange market is very shallow and the CBT has a dominant position in the market.

7. Civcir (2003) reported that currency substitution does not seem to undermine the stability of the money demand in Turkey.

8. The other largest U.S. currency holders are: Russia (80 billion), China (50 billion), Argentina (50 billion) and Korea (15 billion).

9. According to the FED study, USD 15 billion hard-currency is held in Saudi Arabia, Bahrain, the United Arab Emirates, Kuwait, Iran, and Iraq (FED, 2003).

10. See Canales-Kriljenko (2003) and Canales-Kriljenko et al. (2003) on official intervention practices in developing and transition economies. Domaç and Mendoza (2002) studied the effectiveness of interventions under the inflation targeting regime in Turkey and Mexico.

11. Prior to 2001 stabilization program, an exchange rate basket of TRL/USD and TRL/DEM (with weights 60 percent and 40 percent, respectively) was considered as the average nominal exchange rate of the economy. During and after the 2001 program, the official nominal exchange rate basket of the CBT is announced as 1 TRL/USD plus 0.77 TRL/EUR and we used this basket.

12. See Agénor et al. (1997), Doroodian et al. (2002), Erlat (2003) and Ozlale and Yeldan (2004) on the real exchange rate dynamics in Turkey.

13. The CBT indices show that the real appreciation between 1995 and July 2003 is in between 35 percent (WPI based) and 45 percent (CPI based). The figure in the text is based on the Reuters TRTWIN index which is designed and regularly updated by the author.

14. Rodrik (1991) provides a critical analysis of the Turkish liberalization experience. See Rodrik (1998) on the welfare implications of capital-account liberalization in general.

15. Kamin and Rogers (2000) derive and estimate several VAR models to investigate the relationship between the real exchange rate and output in Mexico.

\section{References}

Agénor, P., C.J. McDermott, and E.M. Uçer (1997) "Fiscal Imbalances, Capital Inflows, and the Real Exchange Rate: The Case of Turkey." IMF working Paper, WP/97/1.

Allen, M. et al. (2002) "A Balance Sheet Approach to Financial Crisis." IMF Working Paper, WP/902/210.

Alper, C.E. and Z. Öniş (2003) "Financial Globalization, the Democratic Deficit, and Recurrent Crises in Emerging Markets: The Turkish Experience in the Aftermath of Capital Account Liberalization." Emerging Markets Finance and Trade 39:5-26.

Berument, H. and Pasaogullari, M. (2003) "Effects of the Real Exchange Rate on Output and Inflation: Evidence from Turkey." The Developing Economics 41(4):401-435.

Canales-Kriljenko, J.I. (2003) "Foreign Exchange Intervention in Developing and Transition Economics: Results of a Survey." IMF Working Paper WP/03/95.

Canales-Kriljenko, J.I., R. Guimãraes, and C. Karacadağ (2003) "Official Intervention In the Foreign Exchange Markets: Elements of Best Practice." IMF Working Paper, WP/03/152.

Cavallo, M. et al. (2002) "Exchange Rate Overshooting and the Costs of Floating." Mimeo, New York University.

CBT (2002) "Monetary Policy and Exchange Rate Policy in 2002 and Propective Developmentts." The Central Bank of the Republic of Turkey. Basic Policy Readings. http://www.tcmb.gov.tr.

- (2003) "General frame work of the monetary and exchange rate policy in 2003." The Central Bank of the Republic of Turkey. Basic Policy Readings. http://www.tcmb.gov.tr.

Celasun, O., R.G. Gelos, and A. Prati (2003) "Would "Cold Turkey" Work in Turkey?" IMF Working Paper, WP /03/49. 
Civcir, I. (2003) "Money Demand, Financial Liberalization and Currency Substitution in Turkey." Journal of Economic Studies 30(5):514-534.

Devereux, M.B. and P.R. Lane (2003) "Exchange Rates and Monetary Policy in Emerging Market eEconomies." Mimeo.

Domaç, İlker and M. Bahmani-Oskooee (2002) "On the Link Between Dollarization and Inflation: Evidence from Turkey." The Central Bank of the Republic of Turkey, Discussion Paper.

Domaç, Illker and A. Mendoza (2002) "Is There Room for Forex Interventions Under Inflation Targeting Framework? Evidence From Mexico and Turkey." The Central Bank of the Republic of Turkey, Discussion Paper.

Doroodian, K., C. Jung, and A. Yücel (2002) "Estimating the Equilibrium Real Exchange Rate: The Case of Turkey." Applied Economics 34:1807-1812.

Erlat, H. (2003) "The Nature of Persistence in Turkish Real Exchange Rates." Emerging Markets Finance and Trade 39:70-97.

Ertuğrul, A. and F. Selçuk (2002) "Turkish Economy: 1980-2001." In A. Kibritçioğlu, L. Rittenberg and F. Selçuk (eds.), Inflation and Disinflation in Turkey, Aldershot: Ashgate Publishing Company.

Faruqee, H. (2004) "Exchange Rate Pass-Through in the Euro Area: The Role of Asymmetric Pricing Behavior." IMF Working Paper, WP/04/14.

FED (2003) "The Use and Counterfeiting of United States Currency Abroad, Part 2." The Federal Reserve Board, Reports to the Congress.

Gençay, R. and F. Selçuk (2005) "Overnight Borrowing, Interest Rates and Extreme Value Theory." European Economic Review, forthcoming.

Gençay, R., F. Selçuk, and B. Whitcher (2001) An Introduction to Wavelets and Other Filtering Methods in Finance and Economics. Academic Press, San Diego.

Kamin, S.B. and J.H. Rogers (2000) "Output and the Real Exchange Rate in Developing Countries: An Application to Mexico." Journal of Development Economics 61:85-109.

Kibritçioğlu, A., L. Rittenberg, and F. Selçuk (2002) Inflation and Disinflation in Turkey. Ashgate Publishing Company, Aldershot.

Leigh, D. and M. Rossi (2002) "Exchange Rate Pass-Through in Turkey." IMF Working Paper, WP/02/204.

Lim, C.H. and L. Papi (1997) "An Econometric Analysis of Determinants of Inflation in Turkey." IMF Working Paper, WP/97/170.

Metin, K. (1995) "An Integrated Analysis of Turkish Inflation." Oxford Bulletin of Economics and Statistics 57:513-531.

Metin-Özcan, K., E. Voyvoda, and A.E. Yeldan (2001) "Dynamics of Macroeconomic Adjustment in a Globalized Developing Economy: Growth, Accumulation and Distribution, Turkey 1969-1999." Revue Canadienne d'Etudes du Developpement 22:219-253.

Ozlale, U. and E. Yeldan (2004) "Measuring Exchange Rate Misalignment in Turkey." Applied Economics 36:1839-1849.

Reuters (2003) "U.S. Says Most Iraqi Cash Taken by Qusay is Recovered." Reuters News Agency, May 15, 2003.

Rodrik, D. (1991) "Premature Liberalization, Incomplete Stabilization: The Özal Decade in Turkey." In M. Bruno et al. (eds.), Lessons of Economic Stabilization and Its After math, Cambridge, MA: MIT Press.

(1998) "Who Needs Capital Account Convertibility?" Princeton Essays in International Finance (207):55-65.

Selçuk, F. (2001) "Seigniorage, Currency Substitution, and Inflation in Turkey." Russian and East European Finance and Trade 37:47-57.

- (2003) "Currency Substitution: New Evidence From Emerging Economies." Economics Letters 78:219-224.

Sims, C.A. (1980) "Macroeconomics and Reality." Econometrica 48:1-48.

Us, V. (2003) "Analyzing the Persistence of Currency Substitution Using a Ratchet Variable: The Turkish Case." Emerging Markets Finance and Trade 39:58-81. 